\title{
FAILURE OF EXPANSION JOINT TIE RODS - IMPACT ON BELLOWS INTEGRITY (U)
}

\author{
WSRC-MS- $-92-239$
}

by W. L. Daugherty

Westinghouse Savannah River Company

DE93 007453

Savannah River Site

Aiken, South Carolina 29808

Other Authors:

R. F. Miller

(WSRC)

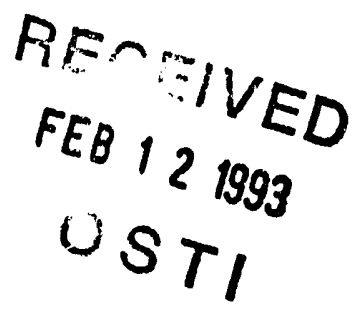

A paper proposed for Presentation/Publication

at/in the 12th International Conference on Structural Mechanics in Reactor Technology

Stuttgart, Germany

08/15-20/93

This paper was prepared in connection with work done under Contract No. DE-AC09-89SR18035 with the U. S. Department of Energy. By acceptance of this paper, the publisher and/or recipient acknowledges the U. S. Government's right to retain a nonexclusive, royalty-free license in and to any copyright covering this paper, along with the right to reproduce and to authorize others to reproduce all or part of the copyrighted paper. 


\section{DISCLAIMER}

This report was prepared as an account of work sponsored by an agency of the United States Government. Neither the United States Government nor any agency thereof, nor any of their employees, makes any warranty, express or implied, or assumes any legal liability or responsibility for the accuracy, completeness, or usefulness of any information, apparatus, product, or process disclosed, or represents that its use would not infringe privately owned rights. Reference herein to any specific commercial product, process, or service by trade name, trademark, manufacturer, or otherwise does not necessarily constitute or imply its endorsement, recommendation, or favoring by the United States Government or any agency thereof. The views and opinions of authors expressed herein do not necessarily state or reflect those of the United States Government or any agency thereof.

This report has been reproduced directly from the best available copy.

Available to DOE and DOE contractors from the Office of Scientific and Technical Information, P. O. Box 62, Oak Ridge, TN 37831; prices available from (615) $576-8401$.

Available to the public from the National Technical Information Service, U. S. Department of Commerce, 5285 Port Royal Rd., Springfield, VA 22161. 
Failure of Expansion Joint Tie Rods - Impact on Bellows Integrity

\author{
W. L. Daugherty and R. F. Miller \\ Savannah River Technology Center \\ Westinghouse Savannah River Company \\ Aiken, SC USA
}

\begin{abstract}
Expansion joints are used in piping systems to accomodate pipe deflections during service and to facilitate hitup. Often, tie rods are employed to limit the range of axial deflection. Additional restraint against excessive displacement can be provided by the surrounding pipe and associated supports. This paper presents a methodology that was employed to estimate the consequences of tie rod litilure. Of particular interest is whether tie rod failure can lead to sufficient displacement as to causc bellows rupture.
\end{abstract}

Expansion joints with four tie rods are in use at the Savannah River Site. This provides sufficient reclundancy against the isolated failure of a single tie rod. However, if two or more tie rods were to fail, the possibility exists for large rotation and extension of the bellows. Specific calculations have heen made of the consequences of failure of three and four tie rods using the AUTOPIPE computer codc to model the piping system. Failure of three tie rods leads to minor rotation only, less than 1 degrec in magnitude. Failure of all four tie rods produces an additional axial extension of about 6.3 inches $(16 \mathrm{~cm})$ under normal operating loads.

The impact of these deflections on the expansion joint bellows has been evaluated. The ABAQUS compulcr code was used to construct both 2D and 3D finite element models of the bellows. These models were used to 1) confirm the AUTOPIPE-calculated displacements with all tie rods failed, and 2) estimate the bellows strain resulting from stretchout. The bellows strain from stretchout is combined with the fabrication strain to estimate the margin to failure that remains. In order for this comparison to he valid, the equivalent uniaxial strain for each step is calculated and compared to the failure strain from uniaxial tensile tests. Large margins to failure are calculated, indicating that hellows rupture will not result from tie rod failure.

\title{
BACKGROUND
}

Expinsion joints are typically used in piping systems to accomodate pipe deflections under thermal loads and to lacilitate fitup. Since the expansion joint is inherently very flexible, some provision such as the use of tie ruds is often required to prevent hyperextension of the bellows. Expansion joints containing 4 tie rods are used in the K Reactur secondary cooling water system (CWS). Any onc of these tie rods can fail without any adverse consequences on operation - the remaining three lic rods will prevent rotation or extension of the bellows past preset limits. However, in the event ol liailure of two or three tie rods, the possibility of bellows rotation exists, depending on the forces ar. $($ moments imposed by the surrounding pipe structure. A single tie rod has sufficient strength to prevent excessive hellows extension. Therefore, hyperextension of the bellows will occur only in the unlikely event of failure of all four tie rods.

Figure I shows a schematic of the CWS expansion joint. Two expansion joint designs, from dilfierent vendors, are used in this CWS application. Both expansion joint designs have been anily\%d, hut results are presented in this paper for only one design, for simplicity. (Results are similar for the other design.) The presence of equilizing rings helps stiffen the bellows, reducing the exlension under a given load. The consequences of tie rod failure are of importance in detcrmining the potential for producing bellows rupture and subsequent core damage. In the event of tic rod failure, the possibility exists for the bellows to be stretched to the point of failure. 
The tic rods are constructed of AISI C- 1141 , with 1.5 inch diameter. The axial thrust load on each lic rod firom normal operating pressure produces an axial stress of $2.0 \mathrm{ksi}$. Even with three tie rods liailed, the stress in the remaining tie rod is well below allowable values. The bellows is made of Type $3(14$ austenitic stainless steel.

In the event of failure of two or more tie rods, the potential for bellows rotation or extension is delemined by the stiffnesses of the bellows and the adjoining piping. In practice, the bellows response will be dominated by either the bellows or the surrounding piping, whichever provides grcilcr resistance against the applied loads.

\section{DISCUSSION}

The expansion joints which were analyzed are located in a relatively flexible run of piping. Unstream is a solid anchor point. Downstream, the pipe changes direction and elevation several limes, wilh relatively few supports. Therefore, the potential exists for relatively large

displacements. Of the several lines containing expansion joints, the most flexible line (the line with the largest displacements with all tie rods intact) was selected for more detailed analysis as a hounding casc with tie rods failed. The general layout of this line is shown in Figure 2.

Upon liailure of three tie rods, the internal pressure load will produce an applied moment at the expansion joint flange due to the load path shifting from the joint centerline to the single remaining lic rod. With an internal pressure load of 10,763 pounds, and a moment arm from the expansion foint centerline to the tie rod of 18 inches, the moment applied to the pipe is 194,000 inch-pounds. Will all four tic rods failed, the internal pressure load path does not shift, but the relatively elastic hellows must transmit the pressure load. The AUTOPIPE computer code was used to estimate the pipe response to these two load conditions.

Pipe Response Analysis

AUTCPIPE is an engineering analysis computer code for modeling and analyzing piping systems. In this application, AUTOPIPE was used to estimate pipe displacements under applied loads, including pressure, thermal, deadweight and seismic. Seismic loads were included in the base case (all lic rods active) for information. Since a single tie rod is sufficient to resist axial seismic design loists, liailure of two or more tie rods during a seismic event is not considered credible. Rather, fitilucic is postulated to occur during normal operation due to fatigue, corrosion, or some other mcchanism. Inclusion of seismic loads in the model with one or more tie rods failed was not pracilical, hased on the modelling techniques used and limitations of the computer code.

The intcrnal expansion joint model was used, which includes features representing the bellows stiliness against axial, lateral and rotational movement, tie rod stiffness, and tie rod gap. The tie rod gap specifies the distance of bellows travel allowed before the tie rod nuts engage to take axial load. limiting total hellows compression or extension. Simulation of all four tie rods failed was accomplished by specifying a gap size larger than the resulting axial displacement. Comparing the risults to the specified gap size confirmed that the selected gap size was appropriate.

Key input parameters are listed in Table 1. In the absence of vendor data, the bellows stiffness valicis lerive firom several sources. The bellows axial stiffness and lateral stiffness are derived firom linitc element computer models of the bellows. The ABAQUS computer code was used to analy $\%$ a 2-dimensional model for the axial stiffness, and a 3-dimensional model for the lateral stiliness. The 2-dimensional model used two-noded axisymmetric elements that allow transverse shear. The 3-dimensional model used four-noded doubly-curved shell elements.

The axial response curve, calculated from the 2-dimensional model, is shown in Figure 3 . It is noted that for loads up to and exceeding the nominal pressure thrust load of 10,763 pounds, the spring ralc (slope) is relatively constant, therefore an average stiffness value will give reasonable resuits for a wide range of ioading conditions. 
Tahle I. Expansion Joint Design Parameters

Parameter

Bellows axial stifiness

Bellows lateral stiffness

Bellows bending stiffness

Bcllows torsion stiffness

Tic rod stilfiness

Tic rod gap
Value

$2020 \mathrm{lb} / \mathrm{inch}$

$3750 \mathrm{lb} /$ inch

1200 inch-lb/degree

rigid

$4.97 \times 10^{6} \mathrm{lb} /$ inch

2 inches compression,

0 inch extension

The latcral stiffness value is based on the 3-D model, which shows a force of 3750 pounds is recpuired lor a 1 inch lateral deflection. The lateral spring rate is expected to be linear over the range of incerst. Uncertainties in modelling the equalizing rings led to development of the bellows hending stiffness by comparison to another bellows design, for which vendor data is available. This design is of similar construction, utilizing similar equalizing rings. It was assumed that the latio ol hending stiffness to axial stiffness is the same for the two designs. For the second bellows design, this ratio equals 0.594 (inch-lb/degree) / (lb/inch), based on vendor data. Therefore, a hencling stiliness tor the hellows of interest of 0.594 (inch-lb/degree) $/(\mathrm{lb} / \mathrm{inch}) * 2020 \mathrm{lb} / \mathrm{inch}=$ 12()() inch-lh/degree was used.

Four cases were run to predict the bellows response to tie rod failure. A base case with all tie rods intact was subjected to deadweight, thermal, pressure and seismic loads. This is the only case that included scismic loads. The second case simulated all four tie rods inactive. The last two cases simulated failure of three tie rods, with the remaining tie rod located on the side or on the top. The results of thesc analyses are summarized in Table 2.

Tahle 2. Tic Rod Failure Analysis Summary

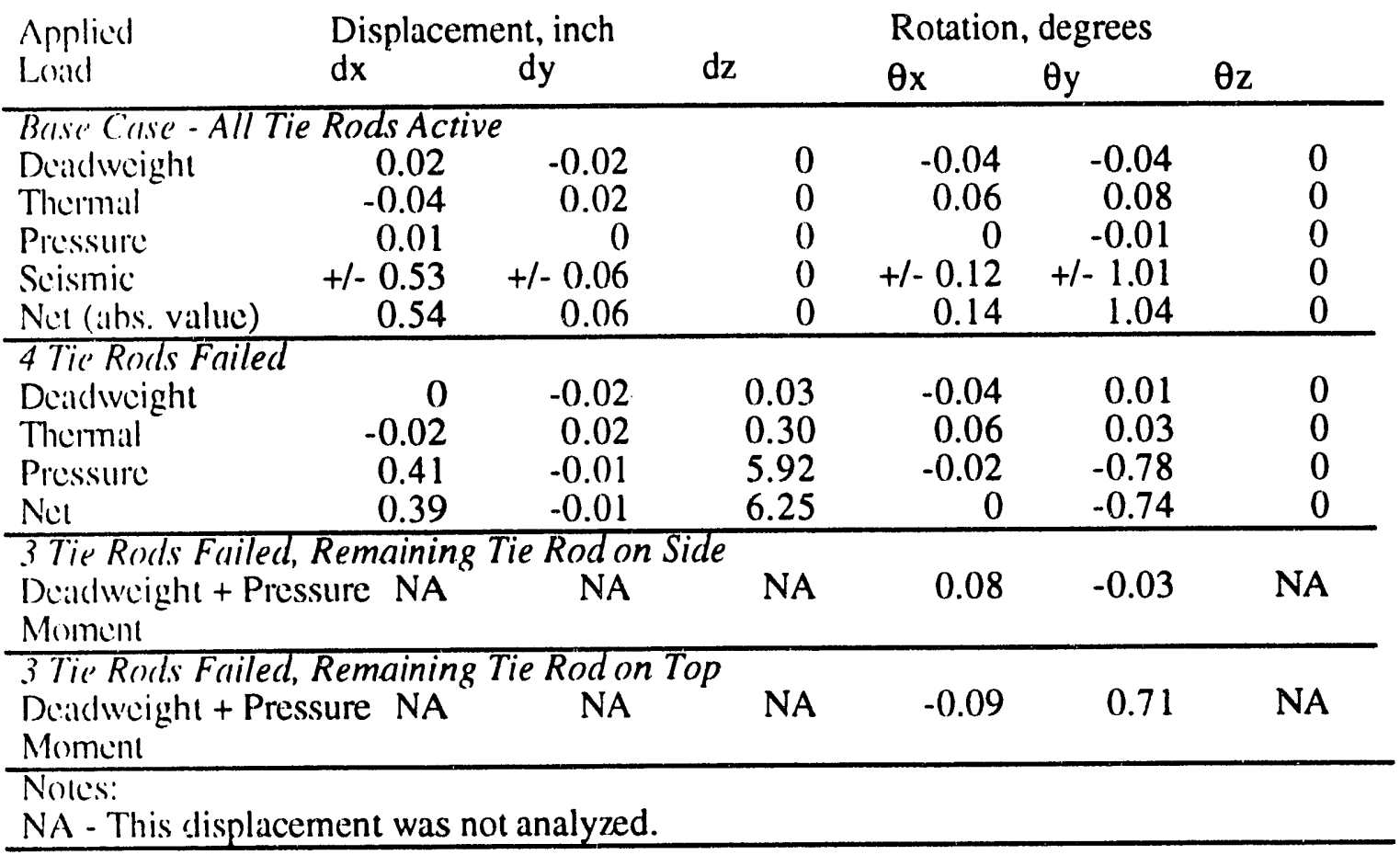


As might he expected, the major displacement in the case of all tie rods failed is axial, with 6.25 inches extension. This displacement results primarily from the applied pressure load. As a check on the modelling technique and results, the finite element bellows model was used to estimate the hellows extension under applied pressure load, ignoring the stiffness of the surrounding pipe. This gavic an cstimated extension under pressure alone of 5.3 inches, in good agreement with the AUT()PIPE result. This agreement may be deceptive, however, given the relative crudeness of the AUTCPIPE modelling and considering that the piping model including the stiffness of the downstream pipe gave a higher extension. Nevertheless, the comparison provides a measure of confickence that the results are reasonable. It also suggests that over this range of deflection the pipe olliers relatively little resistance to bellows extension.

Since the modelling techniques did not allow inclusion of a single active tie rod, the pressure moment in the case of one tie rod active was applied to the downstream flange of the expansion joint and the stifliness of the bellows and remaining tie rod were conservatively ignored. Since this approach produced unrealistical displacement estimates, only rotations are shown in Table 2 . The cistimalled rolations are conservative since the hellows stiffness is ignored.

Since an expansion joint can be installed in a number of orientations with regards to rotation about its axis of symmetry, the tie rods will not necessarily align with the horizontal and vertical axes. Therefore, a hounding estimate of the rotation resulting from failure of three tie rods is obtained firom a square root of the sum of squares (SRSS) combination of the two cases with 1 active tie rod. Combination of the resulting horizontal and vertical components gives a maximum rotation of 0.72 degress.

Bellows Inlegrity Following Tie Rod Failure

Estimalcs of hellows deflections following tie rod failure are only the intermediate step in this analysis. The primary issue is whether such postulated failure will lead to bellows rupture, compromising the system pressure boundary. Finite element models were employed to investigate the impact of postulated tie rod failure on the bellows integrity. Failure of the bellows is assumed to (x'cur if the cumulative strain reaches a critical value - otherwise the bellows will not fail.

Bellows strain derives from two sources. Since the bellows is not solution annealed after liahricition, the strain accumulated during fabrication contributes to the total strain at failure. The sccond contribution is from the displacements due to postulated tie rod failure. Each of these processices produce strain under multiaxial stress states, with a different stress state for each process, and varying from one region of the bellows to another. As a result, direct comparison to simple firilure criteria hased on uniaxial tensile tests is not valid. In order to compare the analysis results to a simple lailure critcrion, the concept of a triaxiality factor is used. Such a factor has been discussed in the literature on several occasions [e.g. reference 1].

The triaxiality factor is defined as:

$$
\begin{aligned}
& \mathrm{TF}=\left(\sigma_{\mathrm{h}}+\sigma_{\mathrm{m}}+\sigma_{\mathrm{r}}\right) / \sigma_{\mathrm{e}} \\
& \text { where: } \quad \mathrm{TF}=\text { triaxiality factor } \\
& \\
& \begin{array}{c}
\sigma_{\mathrm{h}}, \sigma_{\mathrm{m}}, \sigma_{\mathrm{r}}=\text { hoop, meridional, and radial stresses } \\
\sigma_{\mathrm{c}}=\text { equivalent (Mises) stress }
\end{array}
\end{aligned}
$$

The maximum principal strain at a given location is multiplied by the triaxiality factor based on the stressess at that location to give the equivalent uniaxial strain. Equivalent uniaxial strains from scpilralc operations can be added linearly to get the total effective uniaxial strain, a value that can be compared to the failure strain from uniaxial tensile tests. 
Both the labrication process and the effect of bellows extension following tie rod failure have been separalcly modelled with the ABAQUS finite element computer code. Only one-half of a single convolute is modelled, invoking symmetry for the remainder of the bellows. Thirteen axisymmetric shell clements are used to represent the half-convolute. Annealled material properties are used in this model since the bellows material starts out in that state.

The maximum principal strain at any location within the bellows is the hoop strain. Finite element model results show that a good estimate of the hoop strain is given by the ratio of the convolute height to the hellows radius at the convolute root. The finite element model also provides estimates of the principal stresses needed to calculate a triaxiality factor. The maximum principal strain and the highest triaxiality factor both occur at the convolute crest. For this case, the true hoop strain at the crest is $17 \%$, with a corresponding triaxiality factor of 1.32 , giving a maximum equivalent uniaxial strain due to fabrication of $22.4 \%$. The equivalent uniaxial strain drops to less than $1 \%$ at the convolute root.

For the strain due to hellows stretchout following tie rod failure, a 3-dimensional model was constructed. This model invokes two-fold symmetry between the two ends of the bellows and imploys lour-noded doubly-curved shell elements. Ideally, the 3-D model should reflect the variation in material properties from the convolute root to crest, since the fabrication process left the hcllows with varying degrees of cold-work. However, assigning different material properties to cach element is too complex computationally. Therefore, two runs were made, one using annealled propcrtics throughout, and one using properties representative of the maximum cold work at the convolute crest. The results of the first run are reasonable for the lower portion of the convolute near the root, while the second run provides representative results for the convolute crest region. At lociations in hetween an average of results from the two runs is used.

The displacements and rotations estimated for the postulated failure of all tie rods are input to the linitc clement model and the bellows response is calculated. The maximum true strain due to stretchoul following tie rod failure is $2.6 \%$. This strain occurs at the bottom of the flat sidewall region (ncall the root) on the first convolute. (By symmetry, this result applies to the last convolute also.) With a triaxiality factor of 1.75 at this location, the equivalent uniaxial strain is $4.5 \%$.

The results of the finite element analyses of both bellows fabrication and stretchout are plotted in Figure 4. These results are specific to the first or last convolute and are bounding for the other convoluls. The maximum total equivalent uniaxial strain following bellows stretchout is about $25 \%$ and occurs at the convolute crest. This provides a large margin to failure compared to the uniaxial lailure strain of $53 \%$.

This result applies specifically to the bellows response immediately following the postulated failure of all lour tic rods. The estimated large margin to failure, and the relatively small contribution to lotill strain that results from the stretchout itself, provide confidence that failure will not result even will the inodelling approximations that were made. This result does not address the long-term hellow's response, during which the piping system may place relatively large cyclic loads on the strelched-oul hellows. If the degraded condition is not identified shortly after it occurs (short in Lims ol the liequency of plant evolutions that produce cyclic loading), fatigue failure of the bellows is consiclered likely. However, the condition of four failed tie rods and over-extended bellows should he casily spotted when personnel enter the area.

The hellows rotation estimated for postulated failure of three tie rods is less that that for the case of all tic rods lailed. Since the latter case, including additional bellows displacements, is more severe, and large margins to failure were demonstrated, a separate finite element analysis of the case of threc litiled tic rods was not performed. Bellows rupture will not result from the failure of three tie rocis. 


\section{SUMMARY}

Anilysis of the expansion joint response to postulated tie rod failure has been estimated. The hounding case of all four tie rods failed will not lead directly to bellows rupture. Failure of fewer tic rods has correspondingly less severe consequences.

\section{REFERENCES}

1. Manjoine, M. J., 1975, "Ductility Indices at Elevated Temperature", Journal of Engineering Malcrials \& Technology, Volume 97, pp. 156-161.

\section{ACKNOWLEDGMENT}

The information contained in this paper was developed during the course of work done under Conlract No. DE-AC09-89SR18035 with the U. S. Department of Energy. 


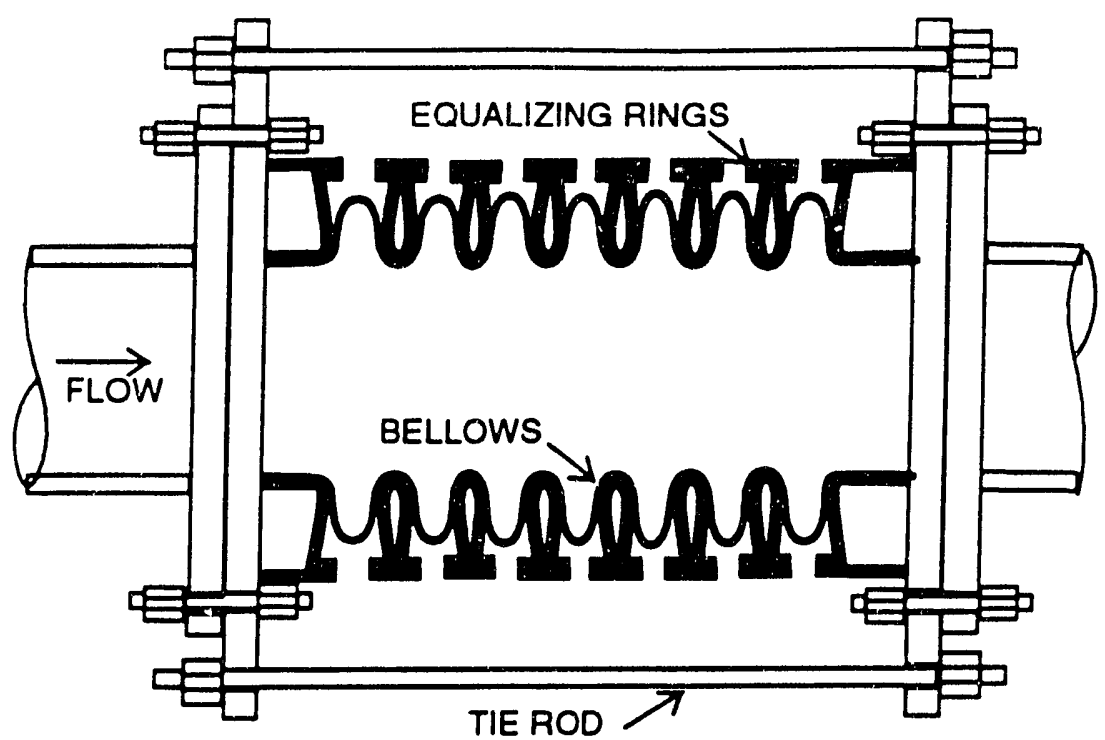

Figure 1. Expansion Joint Schematic

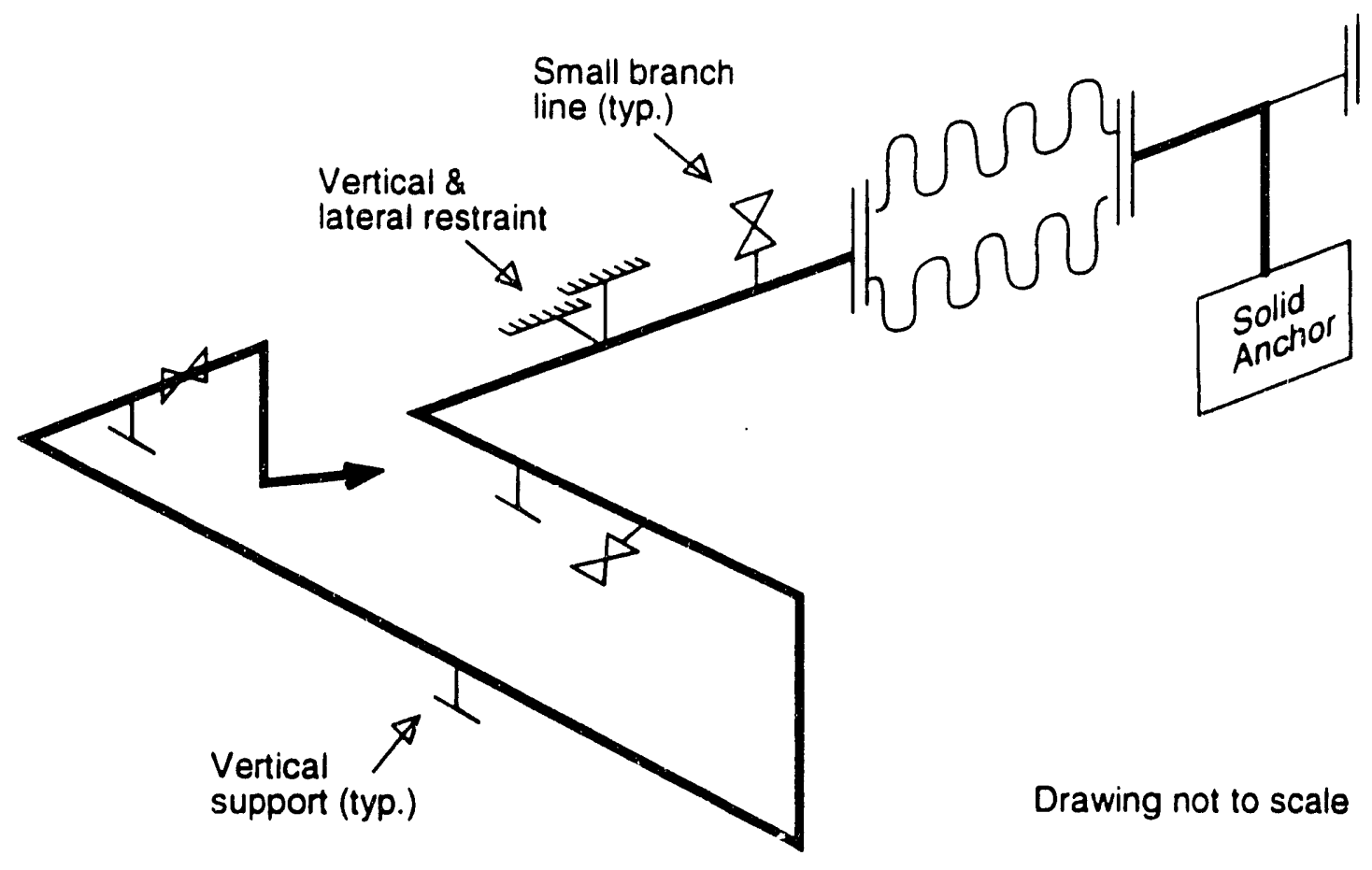

Figur 2. Piping layout schematic 


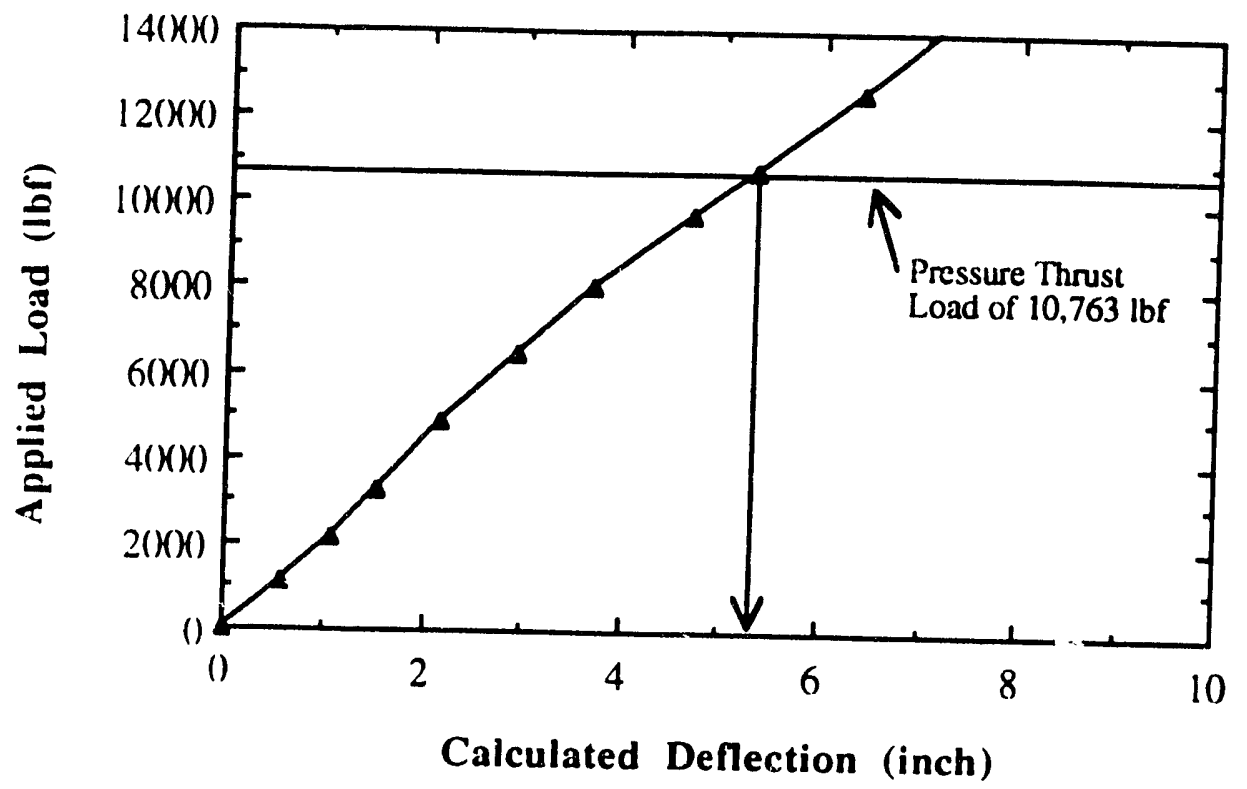

Figure 3. Bellows response to applied axial load

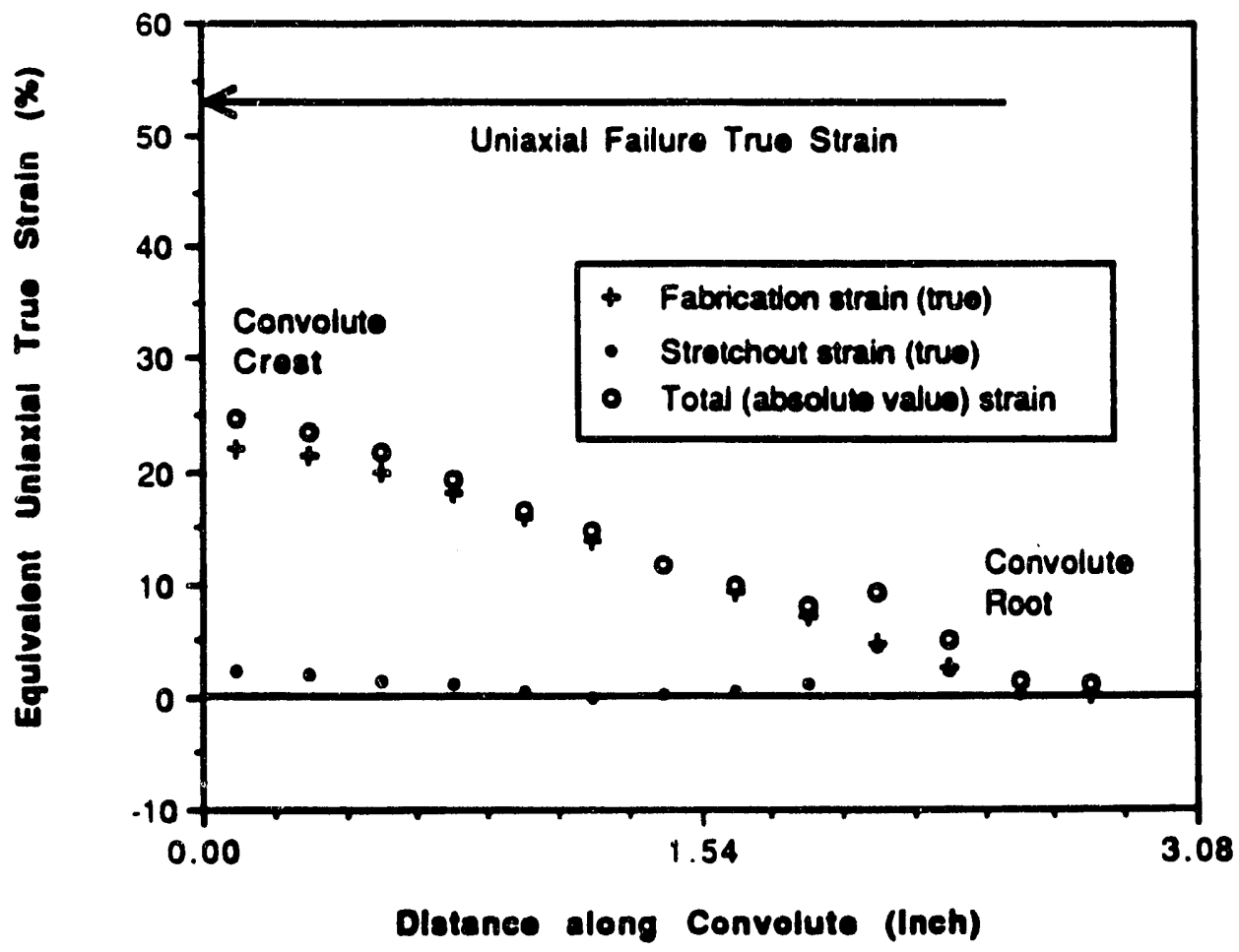

Figurc 4. Equivalent Uniaxial Strain for Bellows Stretchout 

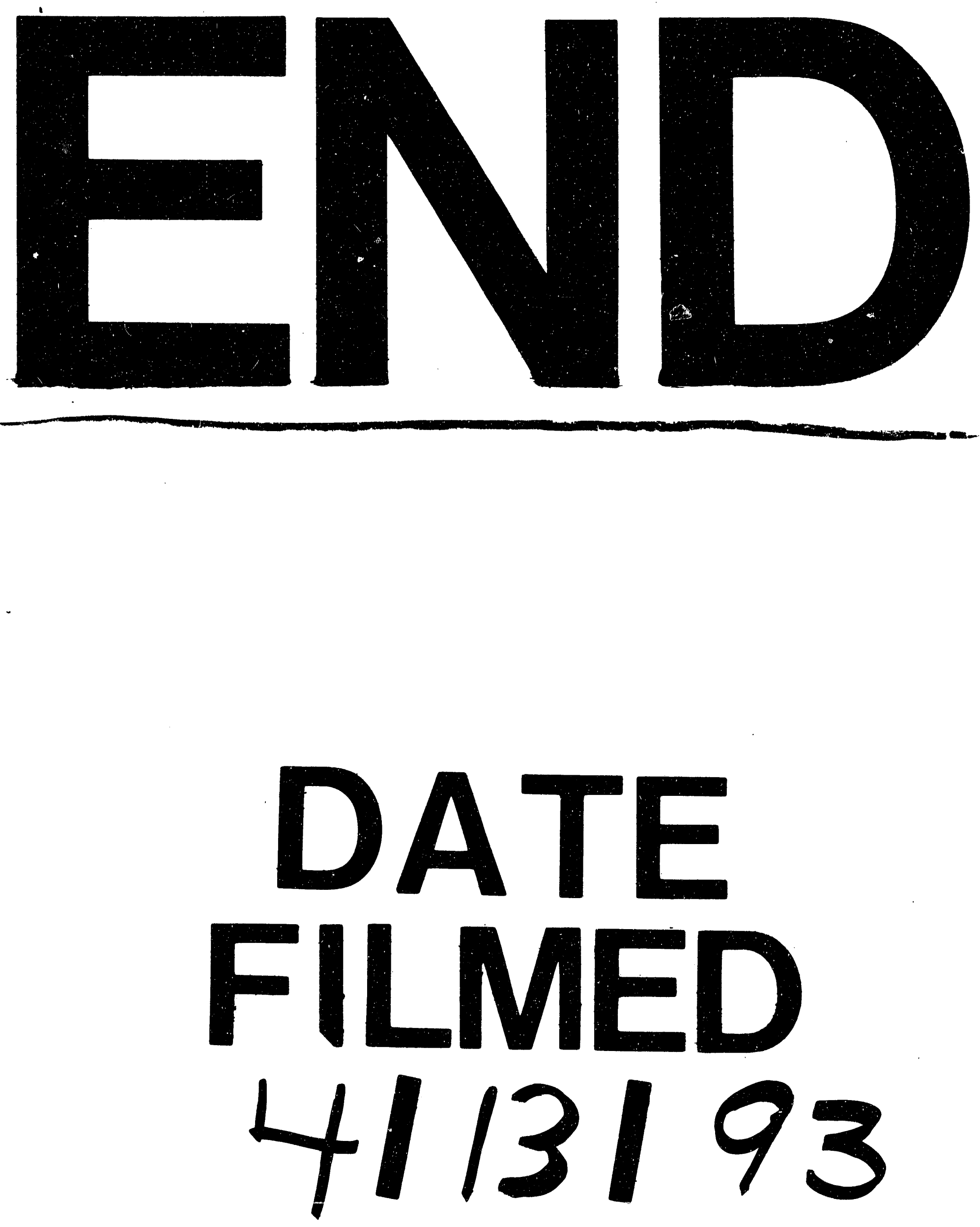

$\overrightarrow{\underline{1}}$ 
1 